\title{
Estimation of Damage in an Underground Mine Due to Effect of Surface Blasting
}

\author{
Ajay Kumar Jha and Debasis Deb \\ Department of Mining Engineering, IIT Kharagpur, Kharagpur-721 302, India
}

\begin{abstract}
Variable Scaling laws predict the blast induced damage in more effective way as compared to fixed scaling law. This study finds that depending on the number and composition of rock strata through which stress waves are transmitted from the surface to underground, $Q^{0.35}$ factors may be appropriate for estimating the scaled distance, which is considered as a measure of PPV (peak particle velocity). Further a new approach is proposed to classify damage of underground structures into three groups (Severe, Moderate, No) using the concept of "Blast Damage Factor" and linear discriminant functions. Site-specific charts between charge weight and distance have been developed so that blasting at a surface mine can be conducted without causing damage to the adjacent underground mine. The study observed that severe roof damage in case study minesite took place when PPV will exceed $54.04 \mathrm{~mm} / \mathrm{s}$ and moderate damage is expected if PPV ranges between $44.68 \mathrm{~mm} / \mathrm{s}$ and $54.04 \mathrm{~mm} / \mathrm{s}$. Any PPV less than $20.00 \mathrm{~mm} / \mathrm{s}$ will produce no damage to underground structures.
\end{abstract}

Key words: Surface blasting, peak particle velocity, predictor equation, blast damage factor.

\section{Introduction}

Coal accounts for about $70 \%$ of total electricity generation in India and is likely to remain a key source for at least the next 30-40 years. The manifold increase in demand for coal puts a huge pressure on augmenting production from opencast mines. In general, near surface (upper) coal seams are mined by opencast methods, while deeper (lower) coal seams are excavated using the Bord and Pillar method. The increase in production within a short period of time demands heavy blasting in overburden and coal benches of opencast mines causing technical as well as socio-political problems due to ground vibration. In this regard, there is a danger to the safety and stability of underground (UG) mine openings, coal pillars, water dams, ventilation and isolation stoppings located in close proximity to operating opencast mines. Prediction of the peak vibration level caused by neighbouring surface mine blasting is important for the safety of underground structures in terms of pillar

Corresponding author: Ajay Kumar Jha, Ph.D., research fields: rock blasting in mines and construction. spalling, roof collapse and junction failure and is normally measured by the PPV (peak particle velocity) [3]. Vibration prediction also helps the surface mine operators to optimise controlled surface blasting with regard to the safety of the underground mine structures.

The root of the problem lies in the nature of vibration that is experienced in underground structures such as pillars, roofs and floors due to blasting conducted in an adjacent surface mine. The problem can be addressed by understanding the characteristics of wave propagation and its attenuation characteristics which are reflected in the wave form received and monitored at observation sites. The attenuation of vibrations chiefly depends on the charge weight, frequency content of wave motion and geomechanical properties of the transmitting medium. The interrelationship among charge weight, distance and amplitude of the motion forms the basis of an attenuation law. Several predictor equations (attenuation laws) of PPV have been developed based on quantity of charge per delay and distance from the source of blasting $[1,2,5,10$, 12]. These equations are mainly used for forecasting PPV at a surface point resulting from blasting at a 
surface mine bench. Peak particle velocity has also been used to evaluate blast damage index at an underground location caused by surface blasting [8]. In most predictor equations, the square root of charge per delay $Q^{1 / 2}$ is assumed to be related to the $\mathrm{SD}$ (scaled distance). However, peak vibration (acceleration and velocity) caused by surface blasting is lower at an underground location compared to a surface point at the same SD [6]. It was proposed that PPV relates to one-third power of charge per delay $Q^{1 / 3}$ for underground locations.

In this study, vibration has been monitored at different locations in roofs, pillars and floors in an underground coal mine, while blasting was conducted at nearby surface coal mine benches. The blast induced vibration data were generated under a Science \& Technology project sponsored by Ministry of Coal, Govt. of India with CMPDI (Central Mine Planning and Design Institute) as the nodal agency and CIMFR (Central Institute of Mining and Fuel Research) and CMPDI as implementing agencies. Peak particle velocities in the underground coal mine roofs, pillars and floors were monitored using geophones. Surface blasting and underground monitoring were synchronized so that the measured vibrations were only due to surface blasting. The monitored data were analysed using statistical techniques, and a new predictor equation of PPV based on distance $R$ and explosive quantity per delay $Q$ was developed. It was found that the power of charge per delay varies with local geological conditions in the best fit model. However, on average, 0.33 power of charge per delay provides a reasonably good estimate of PPVs measured in underground locations if the parting (transmitting) medium is composed of one or two rock stratas.

On the other hand, due to repeated surface blasting, underground structures may also experience loading and unloading phenomena which may be detrimental to the stability of UG structures. As a result, surface mine management may force to restrict the maximum explosive charge per delay leading to planning and carrying out smaller size surface blasts in adjacent surface mines to control the blast vibration in underground within a certain threshold limits. This sub-optimal blasting operation has led to various downstream problems affecting the productivity and economics of the mining activity. Hence, there is an urgent need to understand and determine the threshold PPV up to which underground structures would be safe and can tolerate the blast induced vibration without any significant damage. This paper also elaborates on the development of "Blast Damage Factor (BDF)", based on classification of damage using estimated PPVs, rock mass parameters, pillar and room dimensions, for underground workings arising out of surface blasts carried out in adjacent surface mines [8]. These threshold limits are determined for both the underground mines so that safe and economic surface blasts can be planned without any significant damage potential to underground workings.

\section{Mine Site Description}

Blast vibration measurements were collected from Lajkura OCM (opencast mine)and Orient Mine No. 2 underground mine operated by Mahanadi Coalfields Ltd., a subsidiary of Coal India Ltd. Fig. 1 depicts a schematic view of typical vertical geological sections of the mine site. The case study mine is located in the IB valley coalfield area, which is a part of the large synclinal Gondwana basin of Raigarh-Hingir and Chattisgarh coalfields (Mahanadi valley). The Barakar and Karharbari formations are the major coal bearing formations. The area is generally free from major faults.

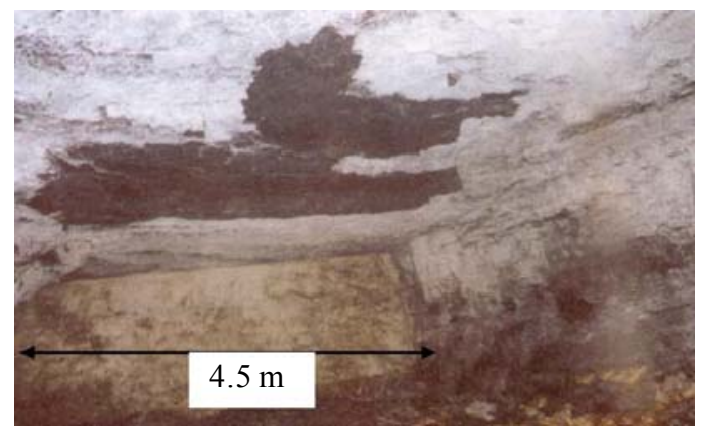

Fig. 1 Photograph showing damaged roof due to blasting. 
Table 1 Description of underground mine and related geotechnical parameters.

\begin{tabular}{ll}
\hline Particulars & Case study mine site \\
\hline Name of the seam & HR_IV Seam \\
Pillar size (corner to corner) $\mathrm{m}$ & $25 \times 25$ \\
Gallery width (m) & 4.5 \\
Gallery height (m) & 2.6 \\
RQD (roof) & 54.5 \\
GSI (roof) & 50.8 \\
Support system & Roof bolting, props and cross bars \\
Average rock density $\left(\mathrm{t} / \mathrm{m}^{3}\right)$ & 2.13 \\
Weighted P wave velocity $(\mathrm{m} / \mathrm{s})$ & 2,602 \\
Rock layers in between surface and underground mines & Lajkura coal seam Sandstone intercalated with sandy shale and shaly sandstone \\
Weighted UCS (MPa) & 23.0 \\
Dynamic tensile strength(MPa) & 6.39 \\
Immediate roof layer up to $2.0 \mathrm{~m}$ & $0.4 \mathrm{~m}$ —Coal, $1.6 \mathrm{~m}$ —-Shale \\
\hline
\end{tabular}

Table 2 Blasting details in case study minesite for overburden bench.

\begin{tabular}{ll}
\hline Particulars & Case study mine site \\
\hline Strata blasted & Shale \\
Hole diameter $(\mathrm{mm})$ & 250 \\
Hole depth $(\mathrm{m})$ & 19.0 \\
Subgrade length $(\mathrm{m})$ & $\mathrm{NIL}$ \\
Burden x spacing $(\mathrm{m} \mathrm{x} \mathrm{m)}$ & $6.0 \times 7.0$ \\
Top stemming $(\mathrm{m})$ & 5.0 \\
Initiation system & Non-electric \\
Explosive type & Emulsion \\
Explosive density $(\mathrm{g} / \mathrm{cc})$ & 1.18 \\
Explosive quantity per hole $(\mathrm{kg})$ & 575 \\
Charge factor $\left(\mathrm{kg} / \mathrm{m}^{3}\right)$ & 0.72 \\
\hline
\end{tabular}

In case study mine site, the Lajkura seam was excavated on the surface, and the HR seam IV was mined underground using Bord and Pillar mining. The average vertical distance between these seams was about $86 \mathrm{~m}$. The inter seam rock layers are mainly composed of sandstone and shaly sandstone. Table 1 lists a brief description of the underground mines and related geotechnical parameters. Table 2 shows blasting details in case study minesite for overburden bench.

\section{Methods}

\subsection{Monitoring of Vibration at Underground Originating from Surface Blast}

Three directional transducer/standard geophones were mounted in the roof, pillar and floor by proper mounting arrangement. Firm contact between rock/coal strata and geophone surface was ensured by placing plaster of Paris as grout material. The mounting stations in the roof were at the junction as well as in between the two junctions of galleries. Geophones were mounted in pillars about $1.0-1.3 \mathrm{~m}$ below the roof surface and by cutting recess/duggy of $0.5 \mathrm{~m}$ inside the pillar from the roof line. Geophones were mounted at least 0.5 to $1 \mathrm{~m}$ inside the roofs and floors. These sensors were connected to the seismographs which were located at a safe location in underground.

Vibrations in terms particle velocity and acceleration were recorded by geophones and stored in the base unit. Surface blasting and underground monitoring timing was planned by observing proper coordination between surface blasting team and underground monitoring team so that vibration in underground structures occurred only due to surface blasting. In case study mine site, a total of 73 observations were recorded at different locations in the roof, pillar and floor. Apart from vibration monitoring, fall of roof, damage in permanent ventilation stoppings and spalling of pillars were also recorded underground right after surface blasting.

\subsection{Classification of Observed Damage}

The severity of the vibration in pillars, roof and floor can be gauged from the fact that the utilization of 10/70 
dragline deployed in the Lajkura OCM has also reduced to as low as $35 \%$ due to blasting technique for ensuring adequate safety measures.

To assess the blast damage accurately, the study area was properly whitewashed so that the fresh fall from roof or pillar, development of new crack or extension of new crack can be visually noticed. Coal blocks detaching from roof having maximum dimension measuring up to $0.25-0.30 \mathrm{~m}^{3}$ is assumed as "Severe damage" type and is shown in Fig. 1. The average size of coal blocks in severe damage type ranged between $0.10-0.15 \mathrm{~m}^{3}$. Some noticeable crack extension and fresh crack development was prominently witnessed in ventilation stoppings. There were number of instances when few loosened chips detached from roof or pillar and coal dust was generated after surface blast in UG workings. This type of damage is termed as "Moderate damage". The instance of no spalling from roof or pillar as well as no new visible crack formation in ventilation stopping and other structures is categorized as "No damage".

\subsection{Development of Predictor Equation}

In this paper, the concepts and results are mentioned below. The attenuation law can be written in general form as Ref. [4],

$$
P P V=K Q^{m} D^{-n}
$$

where,

$Q=$ Charge weight/delay $(\mathrm{kg})$

$\mathrm{D}=$ Distance of the measuring transducer from blasting face $(\mathrm{m})$

$K, \mathrm{~m}$ and $\mathrm{n}=$ Site constants to be determined from the measured data. Eq. (1) can be rewritten in terms of scaled distance as

$$
P P V=K\left(\frac{D}{Q^{s}}\right)^{-n}
$$

where $s=m / n$. Taking natural log in both sides, Eq. (2) becomes

$$
\ln (P P V)=\ln (K)-n \ln \left(\frac{D}{Q^{s}}\right)
$$

In Eq. (3), $K$, s and $\mathrm{n}$ are unknown. By applying least square method, $K$ and $\mathrm{n}$ can be estimated if $\mathrm{s}$ is known. In the following, Eq. (3) has been used to determine value of $K$ and $\mathrm{n}$ for both the mine sites by varying values of $\mathrm{s}$ from 0.1 to 0.75 . The $\mathrm{s}$ value which provides the highest $F$ statistic and $R_{\text {adjusted is }}^{2}$ considered to form the best predictor equation.

\subsection{Development of Blast Damage Factor (BDF)}

In general, several blasting factors (explosive type, explosive charge per delay), rock mass factors (dynamic tensile strength, P-wave velocity and Geological Strength Index of rock strata lying between surface mine to underground mine) and mining factors (size of rooms, distance from blasting site to monitoring station, pillar dimensions and others) can influence damage to $U G$ structures due to surface blasting. A new concept of BDF (Blast Damage Factor) has been developed to assess the damage of underground structures using linear discriminant functions. A chart showing the relationship between $Q$ and $D$ is prepared for different values of PPV and BDF. The relationship can be used as a handy tool for determining safe blasting practices by estimating the explosive charge/delay at any given distance for no damage to the UG structures.

\subsubsection{Definition of BDF}

$\mathrm{BDF}$ is defined to assess the damage of underground mine workings caused by surface blasting. $\mathrm{Yu}$ and Vongpaisal [13] suggested the concept of BDI (Blast Damage Index) for the same purpose. In this study, BDF is defined in terms of induced stress, damage resistance, together termed as Strength Factor, and Mining Factor and given as a dimensionless indicator of damage as:

$$
\begin{aligned}
& B D F= \\
& {[\underbrace{\left[\frac{\text { Induced_Stress }}{\text { Damage_Resistance }}\right]}_{\text {Strength Factor }} \underbrace{\left[\frac{\text { Pillar_Height }}{\text { Pillar_Width }}\right]}_{\text {Mining Factor }} \text { (4a) }}
\end{aligned}
$$




$$
B D F=\left[\frac{P V S \times \rho \times \mathrm{C}_{\mathrm{p}}}{\mathrm{GSI} \times \sigma_{d t s}}\right]\left[\frac{h}{W_{p}}\right]
$$

where, Blasting factor as PVS $=$ Vector sum of PPV in $\mathrm{mm} / \mathrm{s}$ (blasting factor), Rock mass factors as = Density of rock mass in $\mathrm{kg} / \mathrm{m}^{3}, C_{\mathrm{p}}=$ Compressional P-wave velocity of rock mass in $\mathrm{m} / \mathrm{s}, \sigma_{\mathrm{dts}}=$ Dynamic tensile strength of rock mass in $\mathrm{N} / \mathrm{m}^{2}$, and GSI = Geological strength index of rock mass between blasting source and underground mine.

As the name suggests BDF must be inverse of factor of safety. It has two components. The Strength Factor component is a measure of inverse of factor of safety of the underground structures when subjected to blast induced dynamic loading. The numerator, the induced stress is a product of PVS, density of rock mass and compressional $P$ wave velocity of the medium (rock mass). The denominator consists of dynamic tensile strength of intact rock multiplied by the GSI of rock mass. Dynamic tensile strength of rock mass can be approximated by $\sigma_{\mathrm{ci}} / 3.6$ where $\sigma_{\mathrm{ci}}$ is the uniaxial compressive strength of the intact rock [11]. The Mining factor is inverse measure of the strength of coal pillars. The mine working factor is incorporated in BDF to evaluate the contribution of pillar geometry in the stability. In general $W_{\mathrm{p}} / \mathrm{h}$ denotes the slenderness ratio of coal pillar and has been used in pillar strength equation proposed by Bieniwaski and others [7]. Hence, the composite factor will give an indicatory measure of blast induced impact assessment of surface blasts on adjacent underground structures.

For any given mining condition, the variables $\rho, C_{\mathrm{p}}$, $G S I, \sigma_{\text {dts }}$ may be assumed as nearly constant if the roof rock remains the same. The above parameters define the geotechnical properties of rock mass. Under such assumption, it may be inferred that BDF is directly related to PVS. It may be approximated, mathematically, that $B D F=f(P V S)$ and $P V S=h(D, Q)$ where $f(\bullet)$ and $h(\bullet)$ denote the arbitrary functions to be determined from datasets.
3.4.2 Concept of Linear Discriminant Function or Minimum Distance Classification for Generating BDF

Discriminant analysis builds a predictive model for group membership. The model is composed of discriminant functions for more than two groups based on the linear combinations of the predictive variables that provide the best discrimination between the groups [14]. The functions are generated from a sample of cases for which group membership is known. For example, if $\mathbf{x}_{i}$ denotes the centroid or prototype impact pattern of $i^{\text {th }}$ class of data sets then minimum distance linear discriminant function of $i^{\text {th }}$ class becomes,

$$
g_{i}(\mathbf{x})=\mathbf{x}_{i}^{T} \mathbf{x}-\frac{1}{2} \mathbf{x}_{i}^{T} \mathbf{x}_{i} \quad \text { for } i=1,2, \ldots, k
$$

where $k$ denotes the number of class. The function can then be applied to new cases that have measurements for the predictor variables but have unknown group membership. Thus discriminant analysis is used to investigate variables for group separation. A minimum distance classifier computes the distance from pattern $x$ of unknown classification to each known prototype, $x_{\mathrm{i}}$. Then the category number of that closest or smaller distance, prototype is assigned to the unknown pattern, $x$. This concept is also called correlation classification because a closest match is sought between the known prototype pattern and the unknown input pattern.

\section{Results and Discussion}

\subsection{Peak particle Velocity Recorded at Underground Mine}

The average, maximum and minimum of PPVs measured during the field experimentation are listed in Tables 3a-c respectively. It can be noted that geophones were mounted in the roof and floor, roof and pillar, and pillar and floor simultaneously during field measurements. From the measurements, it is found that on an average PPV of roof is twice that of floor and one and half times that of pillar.

A total of 73 sets of vibration data were recorded at mine roofs of Orient No. 2 mine. Out of these data, 6 
Table 3a Average, max., min. and std. dev. of vibration records with geophones mounted at roof and floor.

\begin{tabular}{lllll}
\hline \multirow{2}{*}{ Particulars } & \multicolumn{3}{c}{ Top priming } & Bottom priming \\
\cline { 2 - 5 } & Roof $(\mathrm{mm} / \mathrm{s})$ & Floor $(\mathrm{mm} / \mathrm{s})$ & Roof $(\mathrm{mm} / \mathrm{s})$ & Floor $(\mathrm{mm} / \mathrm{s})$ \\
\hline Average & 83.20 & 33.0 & 89.10 & 36.30 \\
Maximum & 214.70 & 57.1 & 200.0 & 57.79 \\
Minimum & 20.63 & 11.4 & 31.50 & 21.20 \\
\hline
\end{tabular}

Table 3b Average, max., min. and std. dev. of vibration records with geophones mounted at roof and pillar.

\begin{tabular}{lllll}
\hline \multirow{2}{*}{ Particulars } & \multicolumn{3}{c}{ Top priming } & Bottom priming \\
\cline { 2 - 5 } & Roof $(\mathrm{mm} / \mathrm{s})$ & Pillar $(\mathrm{mm} / \mathrm{s})$ & Roof $(\mathrm{mm} / \mathrm{s})$ & Pillar $(\mathrm{mm} / \mathrm{s})$ \\
\hline Average & 24.43 & 16.33 & 29.50 & 19.44 \\
Maximum & 57.75 & 38.50 & 81.80 & 50.80 \\
Minimum & 4.04 & 2.99 & 5.0 & 3.17 \\
\hline
\end{tabular}

Table 3c Average, max., min. and std. dev. of vibration records with geophones mounted at pillar and floor.

\begin{tabular}{lllll}
\hline Particulars & \multicolumn{3}{c}{ Top priming } & Bottom priming \\
\cline { 2 - 5 } & Pillar $(\mathrm{mm} / \mathrm{s})$ & Floor $(\mathrm{mm} / \mathrm{s})$ & Pillar $(\mathrm{mm} / \mathrm{s})$ & Floor $(\mathrm{mm} / \mathrm{s})$ \\
\hline Average & 18.51 & 10.79 & 12.21 & 7.38 \\
Maximum & 44.06 & 26.70 & 26.45 & 17.40 \\
Minimum & 4.91 & 2.92 & 4.13 & 2.50 \\
\hline
\end{tabular}

data sets were recorded at the time of roof damage. The PPV of these 6 data sets are in the range between 169 $\mathrm{mm} \mathrm{s}^{-1}$ and $243 \mathrm{~mm} \mathrm{~s}^{-1}$. The range and average PPV of rest of the data sets are $7.16 \sim 156.6$ and $73.8 \mathrm{~mm} \mathrm{~s}^{-1}$ respectively. In addition, roof fall, pillar spalling and cracks in ventilation stoppings had occurred due to high PPV. Hence, these 6 data, being outliers, are omitted in the subsequent statistical analysis. Using duplex method, $67 \mathrm{PPV}$ data are divided into 50 training data sets and 17 validation data sets [4]. All conventional predictors viz Langefors and Kihlstrom equation, USBM Predictor equation, Ambraseys-Hendron equation, Ghosh Daemen equation, Generalized predictor equation was applied to find the value of $R^{2}$ and $F$ statistics to investigate the fitness of model $[1,2,6,10]$. It was observed that $R^{2}$ and $F$ statistics is the highest in case of generalized predictor equation. The predictor equation is developed based on the training data set and then it is validated using the remaining 17 data. Fig. 2 shows the plot of $R_{\text {adjusted }}^{2}$ and $F$ statistic for various values of s [5]. It can be clearly seen that the best fit model is achieved when $\mathrm{s}=0.35$. The site constant $K$ and $\mathrm{n}$ have been estimated from the training data set. The best fit predictor equation of case study mine site is found to be

$$
\begin{gathered}
P P V=12397\left(\frac{D}{Q^{0.35}}\right)^{-1.573}= \\
12397(S D)^{-1.573}\left(\mathrm{~mm} \mathrm{~s}^{-1}\right)
\end{gathered}
$$

From Fig. 2a, it can be inferred that $\mathrm{s}=0.5$ or square root of charge per delay does not provide the best fit equation, while vibration is measured at an underground location [9]. Fig. 2b depicts the relationship between PPV and scaled distance (SD) of the best fit equation. It shows that PPVs estimated by Eq. (6) matches fairly well with the measured data. The scatter plot between measured (both training and validation data) and estimated PPVs also confirm the fact that the predictor Eq. (6) can be applied to forecast PPVs at underground locations due to surface blasting under similar geological conditions (Fig. 2c).

\subsection{Damage Prediction by Linear Discriminant Functions}

As mentioned earlier, damage has been classified into "Severe, Moderate or No damage" categories. Linear discriminant functions are estimated for these 


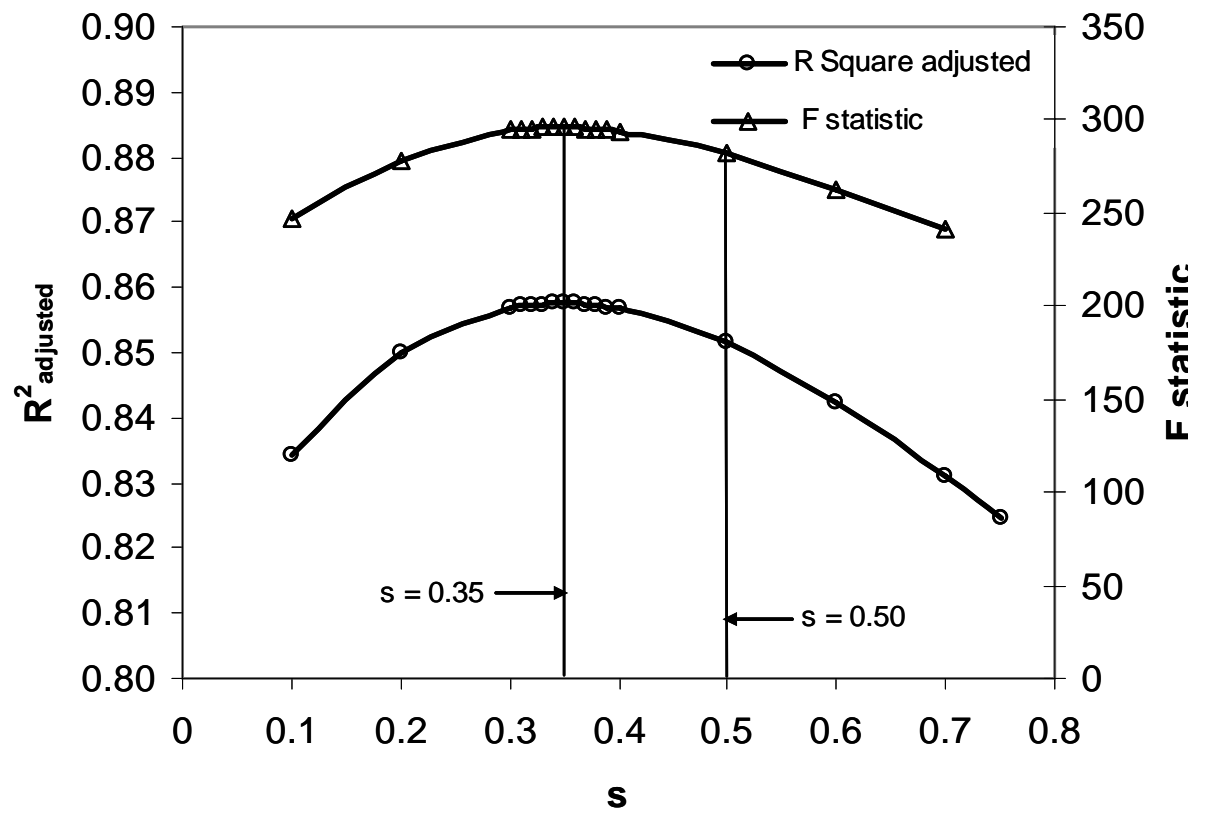

Fig. 2a Relationship of $\boldsymbol{R}_{\text {adjusted }}{ }^{2}$ and F statistic parameter s for case study mine site.

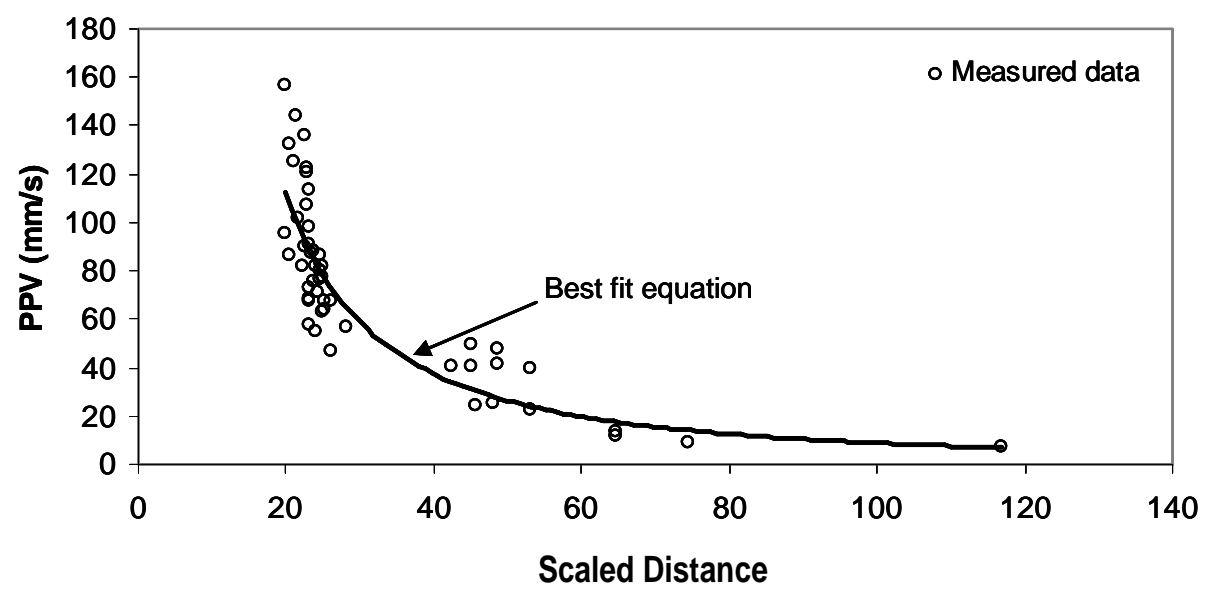

Fig. 2b Relationship between PPV and with scaled distance of case study mine site.

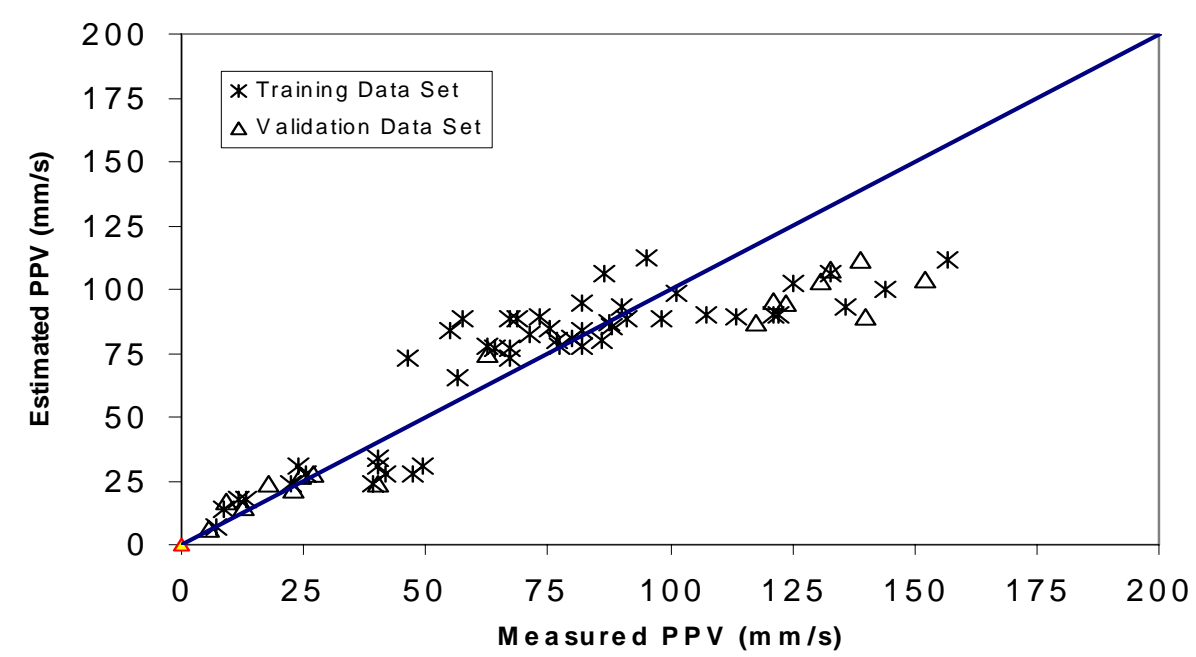

Fig. 2c Relationship between measured and estimated PPV for case study mine site. 
categories or damage classes using predicted PVS. A class Severe or Moderate or No damage is assigned to an unknown observation (BDF) if the estimated value of discriminant function of a particular is the maximum.

Before carrying out the discriminant analysis, the total data have been divided into three parts i.e. training data, validation data and test data in ratio of $75 \%, 15 \%$ and $10 \%$ respectively. The total 73 vibration data recorded at roof of the Orient Mine No. 2 due to surface blasting carried out at the Lajkura OCP, MCL has been divided into 55 training data, 11 validation data and 7 testing data.

Linear discriminant functions are evaluated using estimated PPV data. Based on the criteria mentioned above, training data sets were assigned with a damage class based on the observed phenomena in underground. Then using Eq. (4b), BDF is estimated for each data set. The geotechnical parameters such as density, P-wave velocity, dynamic tensile strength and GSI for computing the BDF is taken from Table 2. Eqs. (7a-c) denote the linear discriminant functions for case study mine site.

$$
\begin{gathered}
g_{\text {severe }}(B D F)=13.43 B D F-90.22 \\
g_{\text {moderate }}(B D F)=11.11 B D F-61.69 \\
g_{\text {unaffected }}(B D F)=4.97 B D F-12.36
\end{gathered}
$$

Linear discriminant functions of Severe, Moderate and No damage classes of a given dataset with known

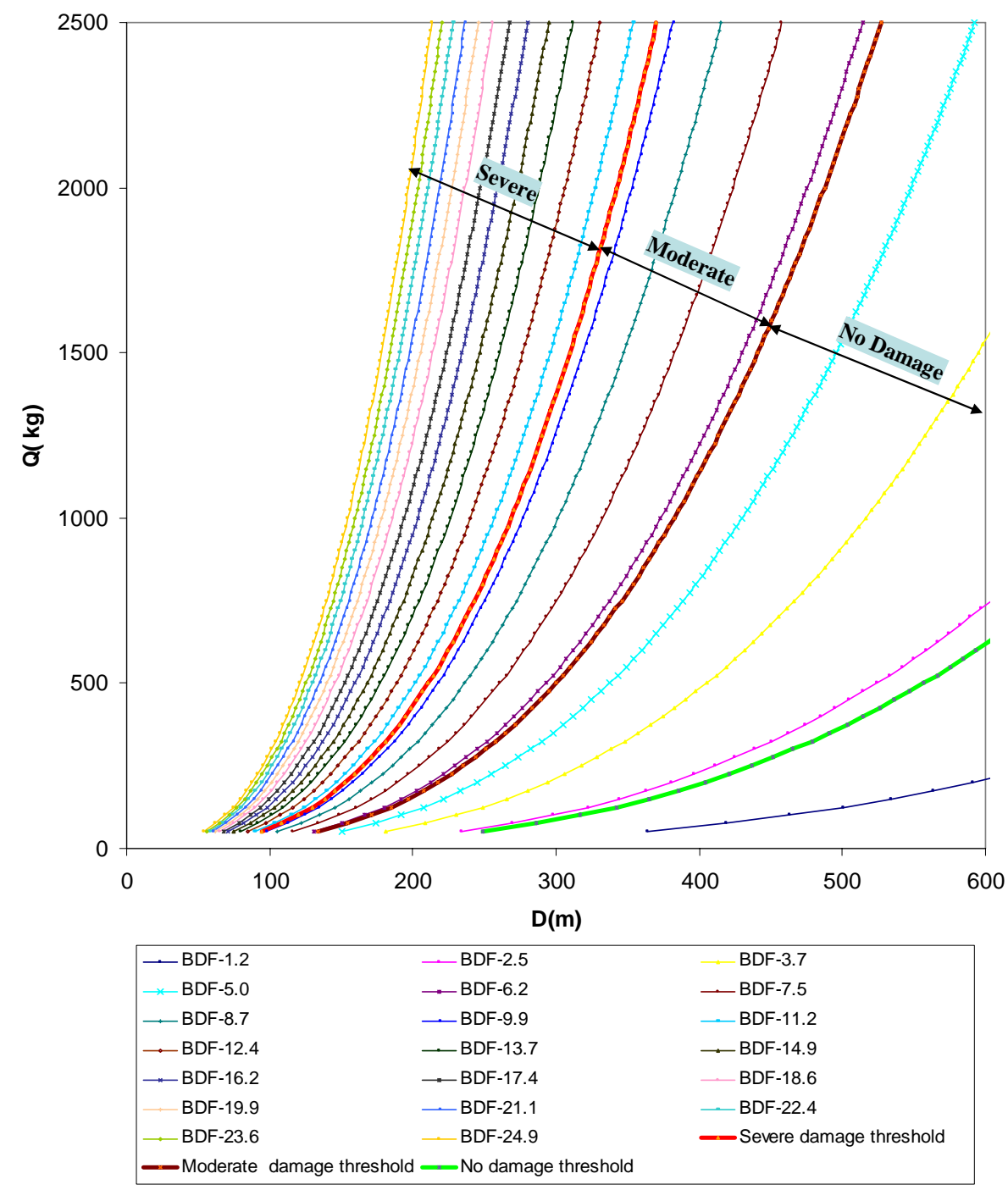

Fig. 3 Relationship between $Q$ and $D$ for case study mine site for different BDF. 
Table 4 Threshold BDF and corresponding PPV for mine site.

\begin{tabular}{llll}
\hline \multirow{2}{*}{ Mine Location } & \multicolumn{3}{l}{ Threshold BDF and PPV $(\mathrm{mm} / \mathrm{s})$} \\
\cline { 2 - 4 } & Severe & Moderate & No \\
\hline Case study Mine site & $6.72,54.04$ & $5.55,44.68$ & $2.49,20.00$ \\
\hline
\end{tabular}

$D$ and $Q$ have been determined based on the estimated PPVs. The results mentioned above are further analyzed to provide working chart for case study mine site based on $Q$ versus $D$ plots for different BDF as shown in Fig. 3. Threshold PPV and BDF values for three damage classes are listed in Table 4 for case study mine site. The results given above can be used as a guideline to determine the damage class and BDF can be obtained if $D$ and $Q$ are known using Fig. 3.

The severe roof damage in case study will take place when PPV will exceed $54.04 \mathrm{~mm} / \mathrm{s}$ and moderate damage is expected if PPV ranges between $44.68 \mathrm{~mm} / \mathrm{s}$ and $54.04 \mathrm{~mm} / \mathrm{s}$. Any PPV less than $20.00 \mathrm{~mm} / \mathrm{s}$ will produce no damage to underground structures.

\section{Conclusions}

In India, there are several locations where coal seams are excavated simultaneously in surface (opencast) and underground (Bord and Pillar) mines. There are considerable stability and safety concerns where surface mine blasting occur in vicinity of underground mines, as this can result in pillar spalling, roof collapse and junction failure as well as an associated loss of coal production. In this study, roof, pillar and floor vibrations were monitored in the Orient No. 2 mine while blasting was carried out at adjacent surface mines. New predictor equations of the PPV have been developed based on the flexible scaled distance law. The roof vibration data of case study mine site was analysed to develop a new predictor equation of PPV at an underground location resulting from surface blasting. Scaled distance based on one-half power (square root) of charge per delay is generally applicable if vibrations are measured at surface points but may not be suitable for predicting PPV at underground installations. The study concludes that 0.35 power of charge per delay can be used to calculate the SD, suggesting use of variable scaling law for vibration predictor equation. It may be concluded that use of variable predictor equation will have higher prediction efficiency to estimate the explosives charge per delay. In future, use of variable scaling law will provide better estimation of blast induced vibration for any mine.

A new dimensionless blast damage factor has been developed for damage prediction of underground roof so that safe blasting can be planned at surface mines with due regard to the safety of underground workings. The threshold BDF and corresponding PPV values of severe damage, Moderate damage and No damage have been estimated using the linear discriminant function for case study minesite. From the study, it may be concluded that PPV less than $20 \mathrm{~mm} / \mathrm{s}$ is unlikely to cause damage to underground structures. Relations between $\mathrm{Q}$ and $\mathrm{D}$ have been developed for different values BDFs for calculating safe explosive charge per delay at any given distance in underground mine workings. These charts can be a handy tool for practicing blasting engineers to ascertain safe charge for any known distance. In future, the use of blast damage factor will provide a handy guideline for estimating the severity of damage arising out of any blasting operation.

\section{References}

[1] Birch, W. J., and Chaffer, R. 1983. "Predictions of Ground Vibrations from Blasting on Opencast Sites." Trans. Inst. Min. Metall. A 92A: A103-7.

[2] Davies, B., Farmer, I. W., and Attewell, P. B. 1964. "Ground Vibrations from Shallow Sub-surface Blasts." Engineer 217: 553-9.

[3] Deb, D., and Jha, A. K. 2010. "Estimation of Blast Induced Peak Particle Velocity at Underground Mine Structures Originating from Neighbouring Surface Mine." Mining Technology 119 (1): 14-21.

[4] Vasovic, D., Kostic, S., Ravilic, M., and Trajkovic, S. 2014. "Environmental Impact of Blasting at Drenovac 
Limestone Quarry.” Environmental Earth Sciences 72 (10): 3915-28.

[5] Duvall, W. I., and Petcoff, B. 1959. "Spherical Propagation of Explosion Generated Strain Pulses in Rock." RI 5483, US Bureau of Mines, Pittsburgh, PA, USA, 21.

[6] Fourie, A. B., and Green, R. W. 1993. "Damages to Underground Coal Mines Caused by Surface Blasting." Int. J. Surf. Min. Reclam.7 (1): 11-6.

[7] Herget, G. 1988. Stresses in Rock. Rotterdam: Balkema.

[8] Jha, A. K. 2015. Investigation of Impact of Surface Blasting on Underground Structures. Germany: Lambert Publication.

[9] Jha, A. K., and Singh, A. K. 2013. "Analysis of Peak Particle Velocity Recorded at Underground Mine Roof Generated by Nearby Surface Blasting: A Case Study." 10th International Symposium on Rock Fragmentation by
Blasting, FRAGBLAST 10, Taylor and Francis Group, London.

[10] Langefors, U., Kihlstrom, B., and Westerberg, H. 1958. "Ground Vibrations in Blasting." Water Power: 335-8, 390-5, 421-4.

[11] Mohanty, B. 1987. "Strength of Rock under High Strain Rate Loading Conditions Applicable to Blasting." Proceedings of the 2nd Symposium on Rock Fragmentation by Blasting, Keystone, USA: 72-8.

[12] Roy, P. P. 1993. "Putting Ground Vibration Prediction into Practice." Colliery Guard 241 (2): 63-7.

[13] Yu, T. R., and Vongpaisal, S. 1996. "New Blast Damage Criteria for Underground Blasting." The Canadian Institute of Mining Bulletin: 139-45.

[14] Zurada, J. M. 1992. Introduction to Artificial Neural systems. New York: West Publishing Company. 